\title{
Chronic Stress Decreases the Number of Parvalbumin-Immunoreactive Interneurons in the Hippocampus: Prevention by Treatment with a Substance P Receptor $\left(\mathrm{NK}_{\mathrm{l}}\right)$ Antagonist
}

\author{
Boldizsár Czeh*,', Mária Simon', Marieke GC van der Hart', Barthel Schmelting', Mayke B Hesselink ${ }^{2}$ and \\ Eberhard Fuchs' \\ 'Clinical Neurobiology Laboratory, German Primate Center, Göttingen, Germany; ${ }^{2}$ Solvay Pharmaceuticals Research Laboratories, C.J. van \\ Houtenlaan, Weesp, The Netherlands
}

\begin{abstract}
Previous studies have demonstrated that stress may affect the hippocampal GABAergic system. Here, we examined whether long-term psychosocial stress influenced the number of parvalbumin-containing GABAergic cells, known to provide the most powerful inhibitory input to the perisomatic region of principal cells. Adult male tree shrews were submitted to 5 weeks of stress, after which immunocytochemical and quantitative stereological techniques were used to estimate the total number of hippocampal parvalbuminimmunoreactive (PV-IR) neurons. Stress significantly decreased the number of PV-IR cells in the dentate gyrus (DG) (-33\%), CA2 $(-28 \%)$, and CA3 (-29\%), whereas the CAI was not affected. Additionally, we examined whether antidepressant treatment offered protection from this stress-induced effect. We administered fluoxetine ( $15 \mathrm{mg} / \mathrm{kg}$ per day) and SLV-323 (20 mg/kg per day), a novel neurokinin I receptor $\left(N K_{1} R\right)$ antagonist, because the $N K_{1} R$ has been proposed as a possible target for novel antidepressant therapies. Animals were subjected to a 7-day period of psychosocial stress before the onset of daily oral administration of the drugs, with stress continued throughout the 28-day treatment period. $\mathrm{NK}_{1} \mathrm{R}$ antagonist administration completely prevented the stress-induced reduction of the number of PV-IR interneurons, whereas fluoxetine attenuated this decrement in the DG, without affecting the CA2 and CA3. The effect of stress on interneuron numbers may reflect real cell loss; alternatively, parvalbumin concentration is diminished in the neurons, which might indicate a compensatory attempt. In either case, antidepressant treatment offered protection from the effect of stress and appears to modulate the hippocampal GABAergic system. Furthermore, the NK, R antagonist SLV-323 showed neurobiological efficacy similar to that of fluoxetine.
\end{abstract}

Neuropsychopharmacology (2005) 30, 67-79, advance online publication, 6 October 2004; doi: I 0. I 038/sj.npp. 130058 I

Keywords: neuroplasticity; antidepressant; interneuron; cell loss; stereology; fluoxetine

\section{INTRODUCTION}

Depressive disorders are common and life-threatening illnesses, but little is known about the underlying fundamental biology (Wong and Licinio, 2001; Nestler et al, 2002). Focus on the monoaminergic system considerably deepened our understanding of the pathophysiology of mood disorders, but examination of the contribution of other neurotransmitter systems to the neurobiology and

\footnotetext{
*Correspondence: Dr B Czeh, Clinical Neurobiology Laboratory, German Primate Center, Kellnerweg 4, 37077 Göttingen, Germany, Tel: + 4955 I 385। 134, Fax: + 4955 I 385। 307,

E-mail: bczeh@dpz.gwdg.de

Received 20 January 2004; revised 13 July 2004; accepted 19 August 2004

Online publication: I September 2004 at http://www.acnp.org/citations/ NPP090 I 0404025/default.pdf
}

treatment of depression is required. Several lines of evidence originating from both animal and human studies suggest the involvement of the GABAergic system in the pathophysiology of depressive disorders (Sanacora et al, 1999; Krystal et al, 2002; Brambilla et al, 2003).

One brain structure that has been extensively studied with regard to the actions of stress, depression, and antidepressant treatment is the hippocampal formation (McEwen, 1999). In humans, numerous imaging studies revealed that the hippocampus undergoes selective volume reduction in several stress-related neuropsychiatric illnesses (Shenton et al, 2001; Bremner, 2002; MacQueen et al, 2003; Sheline, 2003), whereas exposing experimental animals to stress results in structural alterations such as remodeling of the apical dendrites of CA3 pyramidal cells (Magarinos et al, 1996; Kole et al, 2004), marked ultrastructural alterations at the synaptic terminals of the mossy fiber bundle (Magarinos 
et al, 1997), suppression of adult neurogenesis in the dentate gyrus (DG) (Gould et al, 1997), and reduced hippocampal volume (van der Hart et al, 2002). Furthermore, it has been argued that prolonged stress may induce loss of CA3 pyramidal cells, which could contribute to hippocampal atrophy (Sapolsky et al, 1985; Uno et al, 1989), although recent stereological studies questioned the evidence of principal cell loss (Vollmann-Honsdorf et al, 1997; Sousa et al, 1998). Although many studies have investigated the effects of chronic stress on the morphology and number of principal neurons of the hippocampus, few data about possible changes in interneuron numbers are available.

Parvalbumin-containing cells represent a subpopulation of GABAergic interneurons, most prominently chandelier (or axo-axonic) cells and a subset of basket-type interneurons. They selectively innervate the axon initial segments and the somata of cells, and consequently regulate the discharge activity of large populations of principal cells (Kosaka et al, 1987; Ribak et al, 1990; Freund and Buzsaki, 1996). A further important characteristic of these interneurons is that they are fast spiking neurons creating dual networks. Besides, being connected by mutual synaptic contacts, they form a syncytium throughout the hippocampus by dendro-dendritic gap junctions, which is implicated in mediating synchronization of oscillatory activities (Fukuda and Kosaka, 2000). These parvalbumin-containing cells in the hippocampal DG and CA3 region receive most of their excitatory input from granule cells (Seress et al, 2001). Therefore, similarly to CA3 pyramidal cells, parvalbuminpositive interneurons are subjected to the deleterious effect of excessive excitatory amino acid release from the mossy fiber terminals during stress exposure (Magarinos et al, 1997).

In the present study, we investigated whether long-term psychosocial stress could affect the number of parvalbuminimmunoreactive (PV-IR) interneurons in the hippocampal formation. In the first experiment, we examined this in chronically stressed tree shrews, an animal model with high validity for research on the pathophysiology of depression (Fuchs and Flugge, 2002; van Kampen et al, 2002). Additionally, as we did find that stress can affect the number of PV-IR cells, we conducted a second experiment to examine whether treatment with antidepressant drugs offered protection from stress-induced morphological alterations. This experiment was based on recent clinical and preclinical findings, which suggest that depressive disorders may be associated with an impairment of structural plasticity and cellular resilience, and that antidepressant medications may correct this dysfunction (Duman et al, 1999; Manji et al, 2000). Indeed, several studies demonstrated that treatment with various classes of antidepressants could reverse both the functional impairments and the structural alterations of the hippocampal formation induced by stress (Watanabe et al, 1992; Czeh et al, 2001; van der Hart et al, 2002; Herman et al, 2003; Malberg and Duman, 2003; Vermetten et al, 2003; Lucassen et al, 2004). To mimic a realistic situation of antidepressant intervention, we administered the drugs for the clinically relevant period of 4 weeks. We treated animals with fluoxetine, a well-known serotonin selective reuptake inhibitor. Furthermore, we tested a novel neurokinin 1 receptor $\left(\mathrm{NK}_{1} \mathrm{R}\right)$ antagonist, SLV-323 (Czeh et al, 2003;
Hesselink et al, 2003), because the inhibition of the neurokinin substance $\mathrm{P}(\mathrm{SP})$ and its preferred $\mathrm{NK}_{1} \mathrm{R}$ pathway is a promising novel approach to antidepressant treatment (Kramer et al, 1998; Rupniak and Kramer, 1999; Stout et al, 2001). Finally, we preformed an experiment to evaluate whether chronic fluoxetine or SLV-323 treatment of unchallenged animals could affect the number of hippocampal parvalbumin-IR neurons.

\section{MATERIALS AND METHODS}

\section{Animals and Antidepressant Treatment}

For the experiments we used tree shrews (Tupaia belangeri), which are considered to be phylogenetically closely related to primates (Martin, 1990). Experimentally naive adult male tree shrews (mean age $9 \pm 3$ months; $n=46$ ) were obtained from the breeding colony at the German Primate Center (Göttingen, Germany). Animals were housed individually with a $12 \mathrm{~h}$ light/ $12 \mathrm{~h}$ dark cycle and had ad libitum access to food and water (for details see Fuchs, 1999). All animal experiments were in accordance with the European Communities Council Directive of November 24, 1986, (86/EEC) and with the National Institutes of Health Guide for the Care and Use of Laboratory Animals, and were approved by the Government of Lower Saxony, Germany.

Animals received fluoxetine (Ratiopharm, Ulm, Germany) and the highly brain-penetrant $\mathrm{NK}_{1}$ receptor antagonist SLV-323 (Solvay Pharmaceuticals, Weesp, The Netherlands). Drugs were administered orally because this is the most common route of antidepressant administration in psychiatric patients. Moreover, we aimed to minimize uncontrollable stress effects caused by daily injections. We conducted a pilot study to establish the dose of SLV-323 that blocks $\mathrm{NK}_{1}$ receptors in the tree shrew brain. The methodology used is based on the ability of $\mathrm{NK}_{1}$ receptor antagonists to block nicotine-induced vomiting in musk shrews (Tattersall et al, 1995). Adult male tree shrews $(n=4)$ received either vehicle or SLV-323 in different dosage orally followed $30 \mathrm{~min}$ later by subcutaneous administration of $(-)$ nicotine $(4 \mathrm{mg} / \mathrm{kg}$; Sigma-Aldrich), and the number of emetic episodes occurring during the following $30 \mathrm{~min}$ was recorded. Each animal received each treatment in a crossover design, with 10 days washout period between studies. Emetic episodes were abolished by treatment with $20 \mathrm{mg} / \mathrm{kg}$ per day SLV-323, whereas lower doses, that is, 5 or $10 \mathrm{mg} / \mathrm{kg}$ per day and vehicle were ineffective. These results showed that treatment with $20 \mathrm{mg} /$ kg per day SLV-323 could effectively block central $\mathrm{NK}_{1}$ receptors. In another pilot study, the necessary dosage of fluoxetine was determined. Accordingly, we treated the animals with $15 \mathrm{mg} / \mathrm{kg}$ per day fluoxetine, which resulted in a $81-634 \mathrm{ng} / \mathrm{ml}$ plasma concentration of norfluoxetine $24 \mathrm{~h}$ after the last dose in the 4-week treatment period; a similar range is reported for patients under fluoxetine treatment (Laboratory Corporation of America database).

The experimental designs are shown in Figure 1. In the first experiment, we examined whether chronic stress affected the number of PV-IR neurons in the hippocampal formation. A Control $(n=6)$ and a Stress $(n=6)$ group were compared. Animals of the Control group remained singly housed in their cages, while animals of the Stress group were 


\begin{tabular}{|c|c|c|}
\hline Control & & No stress \\
\hline Stress & Pre-stress & stress \\
\hline & 7 days & 35 days \\
\hline
\end{tabular}

b 2nd Experiment

\begin{tabular}{|c|c|c|c|}
\hline Stress & Pre-stress & Stress & stress \\
\hline Stress + Fluoxetine & Pre-stress & Stress & Stress + Fluoxetine \\
\hline \multirow[t]{2}{*}{ Stress + SLV-323 } & Pre-stress & Stress & Stress + NK1R antagonist \\
\hline & 7 days & 7 days & 28 days \\
\hline
\end{tabular}

C

\begin{tabular}{|c|c|c|}
\hline \multicolumn{3}{|c|}{ 3rd Experiment } \\
\hline Control & \multicolumn{2}{|r|}{ No stress } \\
\hline ontrol + Fluoxetine & No Stress & No Stress + Fluoxetine \\
\hline \multirow[t]{2}{*}{ Control + SLV-323 } & No Stress & No Stress + NK1R antagonist \\
\hline & 7 days & 28 days \\
\hline
\end{tabular}

Figure I Experimental design. (a) In the first experiment a Control $(n=6)$ and a Stress $(n=6)$ group were compared, where animals of the Stress group were submitted to daily psychosocial conflict for 5 weeks and the Control group remained undisturbed. (b) In the second experiment a Stress group $(n=5)$, a Stress + Fluoxetine $(n=5)$ and a Stress + SLV-323 (or Stress $+N K, R$ antagonist) $(n=6)$ group were used. The first experimental phase consisted of a 7-day Pre-Stress period. During the second phase, which also lasted 7 days, the animals of the three stress groups (Stress, Stress + Fluoxetine, Stress-SLV-323) were submitted to daily psychosocial conflict, whereas animals of the control group (Control) remained undisturbed. The third experimental phase lasted 28 days. Stressed animals remained in the psychosocial conflict situation and received the drugs (Stress + Fluoxetine, $15 \mathrm{mg} / \mathrm{kg}$ per day; Stress + SLV-323, $20 \mathrm{mg} / \mathrm{kg}$ per day) or vehicle (Stress) orally. In total, the psychosocial stress exposure lasted 35 days. (c) Finally, in the third experiment we treated control unchallenged animals either with fluoxetine (Control + Fluoxetine, $15 \mathrm{mg} / \mathrm{kg}$ per day; $n=6$ animals) or with SLV-323 (Control +SLV-323, $20 \mathrm{mg} / \mathrm{kg}$ per day; $n=6$ animals) or with vehicle (Control; $n=6$ animals) orally for 28 days.

submitted to daily psychosocial conflict for 5 weeks (Figure 1a). Urine samples were collected on a daily basis throughout the whole experiment to monitor the neurosympathetic tone by measuring free norepinephrine in the morning urine.

The induction of psychosocial conflict was carried out according to standard procedures (Fuchs and Flugge, 2002). Briefly, one naive male was introduced into the cage of a socially experienced male. This resulted in active competition for control over the territory, and when a clear dominant-subordinate relationship had been established, the two animals were separated by a wire mesh barrier. The barrier was removed every day for about $1 \mathrm{~h}$, thereby allowing physical contact between the two males during this time only. Using this procedure, the subordinate animal was protected from repeated attacks, but it was constantly exposed to olfactory, visual, and acoustic cues from the dominant animal. Under these conditions, subordinate animals displayed characteristic subordination behavior.

In the second experiment, we examined whether concomitant antidepressant treatment counteracted the chronic stress-induced changes. For this purpose, three experimental groups were used: a second Stress group $(n=5)$, a Stress + Fluoxetine group $(n=5)$ and a Stress $+N K_{1} R$ antagonist $(n=6)$ group (Figure $1 \mathrm{~b})$. The first phase of this experiment (Pre-Stress) lasted for 7 days, during which all animals remained undisturbed (Figure 1b). The second phase was a 7-day period (Stress) during which the animals were submitted to daily psychosocial conflict. The third experimental phase consisted of the antidepressant treatments, which lasted for a clinically relevant period of 4 weeks. During this time, the animals remained in the psychosocial conflict situation and each morning received oral administration of the compounds between 0800 and 0815. Animals of the Stress group were submitted to daily psychosocial conflict for 5 weeks. Urine samples were collected from all animals daily throughout the whole experiment.

Finally, we performed an experiment, to investigate whether treatment of unchallenged animals with either fluoxetine or SLV-323 influences the number of PV-IR cells. This third experiment consisted of a Control $(n=6)$, a Control + Fluoxetine $(n=6)$ group, and a Control $+S L V$ $323(n=6)$ group (Figure 1c). The drug-exposed animals underwent the same treatment protocol as the animals in experiment 2, that is, they received $15 \mathrm{mg} / \mathrm{kg}$ fluoxetine per day, or $20 \mathrm{mg} / \mathrm{kg}$ SLV-323 per day, orally for 28 days.

\section{Perfusion and Brain Tissue Preparation}

Animals were anesthetized with an overdose of xylazin/ ketamine and perfused transcardially with $100 \mathrm{ml}$ of saline followed by $200 \mathrm{ml}$ of fixative containing $4 \% 0.1 \mathrm{M}$ sodiumphosphate-buffered paraformaldehyde ( $\mathrm{pH} 7.4)$. The heads were postfixed in fresh fixative and on the following day, the brains were removed from the skull. After cryoprotection with $0.1 \mathrm{M}$ phosphate-buffered saline (PBS; $\mathrm{pH}$ 7.4) containing $30 \%$ sucrose and $10 \%$ glycerol, a freezing microtome was used to collect serial horizontal $50 \mu \mathrm{m}$ thick sections throughout the dorso-ventral extent of the left hippocampal formation. A stereotaxic brain atlas of the tree shrew (Tigges and Shantha, 1969) was used for reference during the cryosectioning procedures. Every tenth section was selected and processed for parvalbumin immunostaining. Samples from each treatment group were always processed in parallel to avoid any unspecific effect of the staining procedure. Free-floating sections were washed in $0.1 \mathrm{M} \mathrm{PBS}$ and then treated with $1 \% \mathrm{H}_{2} \mathrm{O}_{2}$ for 20 min. After washing, nonspecific binding of antibodies was prevented by incubating the sections for $1 \mathrm{~h}$ with $3 \%$ normal goat serum (NGS; Vector Laboratories, Burlingame, CA, USA) in $0.1 \mathrm{M}$ PBS containing $0.5 \%$ triton-X-100. The sections were subsequently incubated overnight in a mouse monoclonal antibody against parvalbumin (1:3000; Chemicon, Hofheim, Germany) at $4{ }^{\circ} \mathrm{C}$ in $0.1 \mathrm{M}$ PBS containing $0.5 \%$ Triton $\mathrm{X}-100$ and $1 \%$ NGS. The next day, the sections were rinsed several times in $0.1 \mathrm{M}$ PBS, incubated in a biotinylated mouse secondary antibody $(1: 200$; Vector Laboratories, Burlingame, CA, USA) for $2 \mathrm{~h}$, rinsed, incubated in avidinbiotin-horseradish peroxidase (1:200; Vectastaine Elite $\mathrm{ABC}$ Kit, Vector) for $2 \mathrm{~h}$, rinsed again, and developed for 5 min in diaminobenzidine $(1: 200$; DAB Peroxidase Substrate Kit, Vector), and then thoroughly rinsed. The sections were then mounted on glass slides in a $0.1 \%$ gelatin solution and dried overnight, after which they were dehydrated through alcohols, cleared in xylene for $30 \mathrm{~min}$, and finally coverslipped under Eukitt. 
We also evaluated whether using different titers of the primary antibody might affect the number of parvalbuminpositive cells. For this purpose, we used four animals of the stress group and processed three series of serial sections for immunohistochemistry with different titers of the primary antibody (ie $1: 1000,1: 2000,1: 3000$ ). Using this approach, higher concentrations of the antibody should mark cells that express lower levels of PV and result in a higher total number of cells.

\section{Quantification of Parvalbumin-Immunoreactive Cells}

Neuron numbers were estimated with the modified optical fractionator technique (West et al, 1991; West, 1999). The optical fractionator is an unbiased counting method, which is independent of the size, shape, and orientation of the cells to be counted, and combines the optical disector (Sterio, 1984) with the fractionator-sampling scheme (Gundersen et al, 1988). The parameters of the fractionator-sampling scheme were established in a pilot experiment, and were uniformly applied to all animals. For examination, every tenth section (an average of 14 sections per animal) was systematically sampled $\left(f_{1}=10\right)$ through the dorso-ventral extent of the left hippocampus. Before quantitative analysis, slides were coded, and the code was not broken until the analysis was completed. Cell counting was conducted using a Zeiss III RS microscope with the aid of the Stereoinvestigator 3.16 software (Microbrightfield, Colchester, VT, USA; for details of the setup see Keuker et al, 2001). The border of the region was outlined using a $\times 6.3$ objective (NA 0.16), and for counting cells a $\times 16$ (NA 0.16 ) objective was used. The optical disector frame area, $a$ (frame), and the sampling area, $A(x, y$ step), were selected such that $1-3 \mathrm{PV}$ IR neurons per optical disector were counted on average. The size of the disector frame area, $a$ (frame) was $200 \mu \mathrm{m} \times 300 \mu \mathrm{m}$, and the sampling area, $A(x, y$ step $)$ was $300 \mu \mathrm{m} \times 300 \mu \mathrm{m}$, yielding: $f_{2}=a($ frame $) \times 1 / A(x, y$ step $)=$ 1.5. We used the same $a$ (frame) and $A(x, y$ step) for analysis of the DG, CA3 and CA1 regions. Proper optical disector rules require guard zones both at the upper and lower surfaces of the section, but here we applied the modified optical disector method, which means that we did not use guard zones. Thus, the height of the optical disector, $h$, equals the actual section thickness, $t$; hence, the thickness sampling fraction equals $1\left(f_{3}=1\right)$. After having counted all cells $\left(\sum Q^{-}\right)$fulfilling the criteria of sampling, the total number of cells was estimated: $N_{\text {total }}=\sum Q^{-} \times f_{1} \times f_{2} \times f_{3}$.

To verify that the PV antibody penetrated the full thickness of the section, we analyzed several sections from each experimental animal, focusing with a $\times 100$ lens through the entire section thickness. We found that the penetration of the antibody was complete, because labeled cells were detectable in all deeper layers within a given section.

The distinction of subfields and laminae of the hippocampal formation after PV staining is relatively simple (Figure 2) and well described by Keuker et al (2003). Quantification was carried out in the DG and in the three subfields of Ammon's horn (CA1-3). To be able to fulfill the requirements of the stereological approach, namely that there should be 1-2 cells counted on average in each sampling area, we decided to exclude certain layers from the
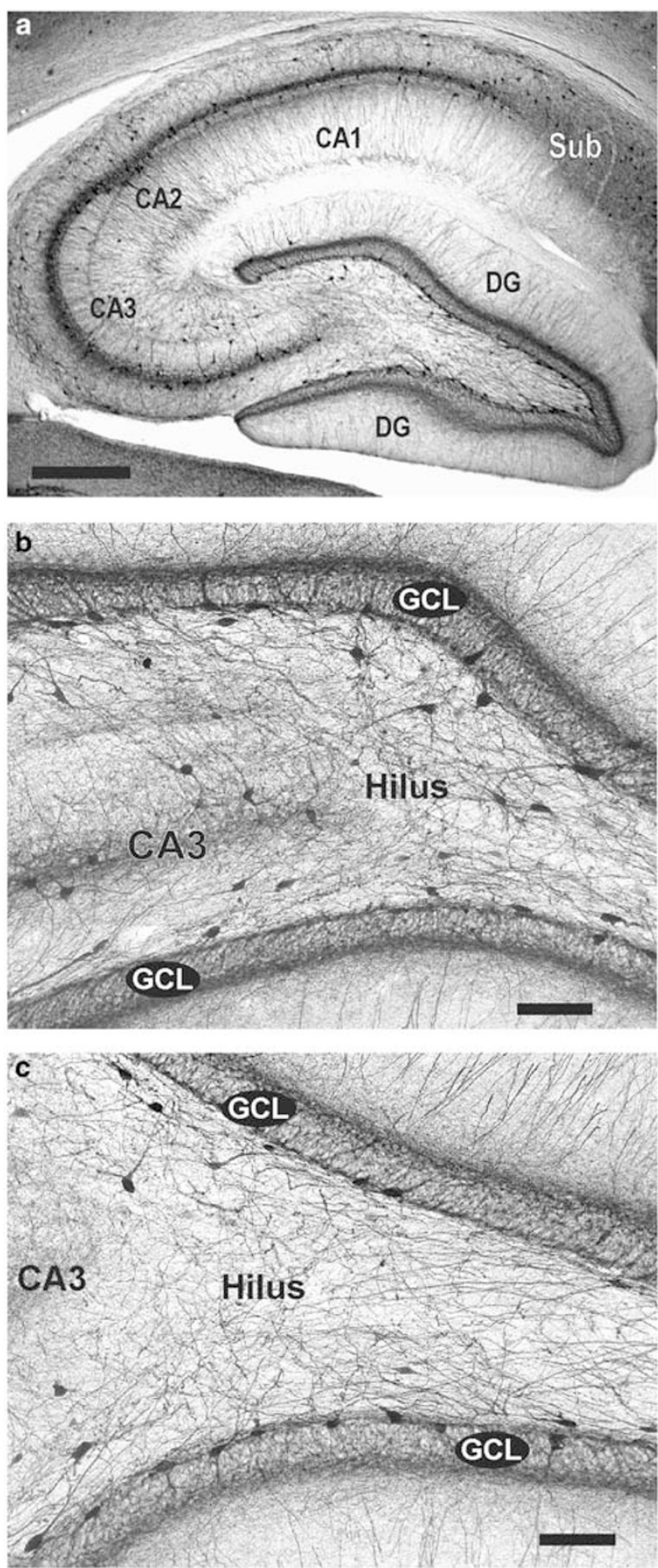

Figure 2 Representative example of a parvalbumin stained horizontal section of the tree shrew hippocampal formation (a). Parvalbuminimmunoreactive neurons were present exclusively as nonprincipal cells. Note that all subregions and layers are clearly distinguishable. Detailed images of the dentate gyrus from a representative control (b) and chronically stressed animal (c). In the dentate gyrus, most of the PV-positive interneurons were aligned at the border of the granule cell layer and the hilus. Furthermore, numerous PV-IR cells were distributed throughout the hilus, and located within the granule cell layer, but such cells in the stratum moleculare were extremely rare. Note the smaller density of PV-positive cells after the long-term stress (c). DG, dentate gyrus; $G C L$, granule cell layer; SUB, subiculum. Scale bars: $500 \mu \mathrm{m}$ (a); $100 \mu \mathrm{m}$ (b, c). 
analysis, namely those where PV-containing cells are extremely rare. Within the DG, most of the PV-IR interneurons are located either in the hilus or in the granule cell layer, and therefore only these two laminae were investigated, excluding the molecular layer from the analysis. In the case of the CA3 area, PV-IR cells were quantified in all strata except the stratum lacunosum moleculare. Within the CA1, PV-positive interneurons are mostly located just above and below the pyramidal cell layer, as well as in the stratum oriens; thus, only these two laminae were analyzed during the quantification and we excluded the stratum radiatum and stratum lacunosum moleculare. As the CA2 region is a very small area, it was presently impossible to apply the essential fractionatorsampling rules. Instead, all PV-IR cells were counted and finally their total number was estimated by multiplying the number of cells counted in every tenth section by 10 .

\section{Analysis of Urine Samples and Testis Weight Measurement}

Analysis of urine levels of norepinephrine and creatinine was performed at KCL Bioanalysis b.v., Leeuwarden, The Netherlands. In brief, urinary norepinephrine was quantified by LC-MS (analytical column; Alure Basics, Restek, $50 \mathrm{~mm}, 2 \mathrm{~mm}$ ID) with electrospray ionization $(5500 \mathrm{~V}$, $200^{\circ} \mathrm{C}$ ) after liquid-liquid extraction. To correct for physiological alteration in urine dilutions, the resulting concentrations were related to creatinine concentrations, which were determined with a Roche Modular P800 clinical chemistry analyzer with creatinine reagents (Jaffe method).

As decreased adrenal and testis weights are indicators of sustained stress exposure, these organs were removed from the animals immediately after perfusion and weighed. Data are expressed as milligrams organ weight per gram average body weight of the preceding week.

\section{Statistical Analysis}

Results are presented as the mean \pm SEM. Treatment effects were assessed with two-tailed unpaired Student's $t$-test or one-way ANOVA, followed by either Student-NewmanKeuls or Tukey's post hoc analysis for further examination of group differences. Importantly, because results of the two Stress groups did not differ significantly in any parameter between the first and second experiments, their values were pooled and presented throughout the article as a single Stress group.

\section{RESULTS}

Activation of the sympatho-adrenomedullary system is an important and reliable indicator by which tree shrews can be classified as subordinates (Fuchs and Flugge, 2002). Animals from the Stress, Stress + Fluoxetine and Stress + $S L V-323$ groups all displayed significantly elevated urinary norepinephrine levels after 5 weeks of social encounters (Figure 3a). Moreover, we measured testis weights because gonadal hypotrophy is an indicator of sustained stress exposure (Fischer et al, 1985). Chronic confrontations significantly reduced testis weights in the animals of the Stress and Stress + Fluoxetine groups, whereas SLV-323 treatment resulted in a highly significant increase in testis weights both in the control and stressed animals (Figure 3b).

Parvalbumin-immunoreactive neurons were present exclusively as nongranule cells of the DG and nonpyramidal cells of the CA1-3 of the Cornu Ammonis (Figure 2). The morphology and distribution of these PV-positive interneurons was similar to what has been described in the tree shrew (Keuker et al, 2003) and rat hippocampal formation (Kosaka et al, 1987).

The first experiment was designed to evaluate whether long-term stress affected the number of PV-IR interneurons in the hippocampal formation (Figure 4). Exposure to chronic psychosocial stress resulted in a significant decrease in the total number of PV-IR interneurons in the DG $\left(-33 \%, t_{17}=3.88, p=0.001\right.$; Table 1$)$, and in the CA3
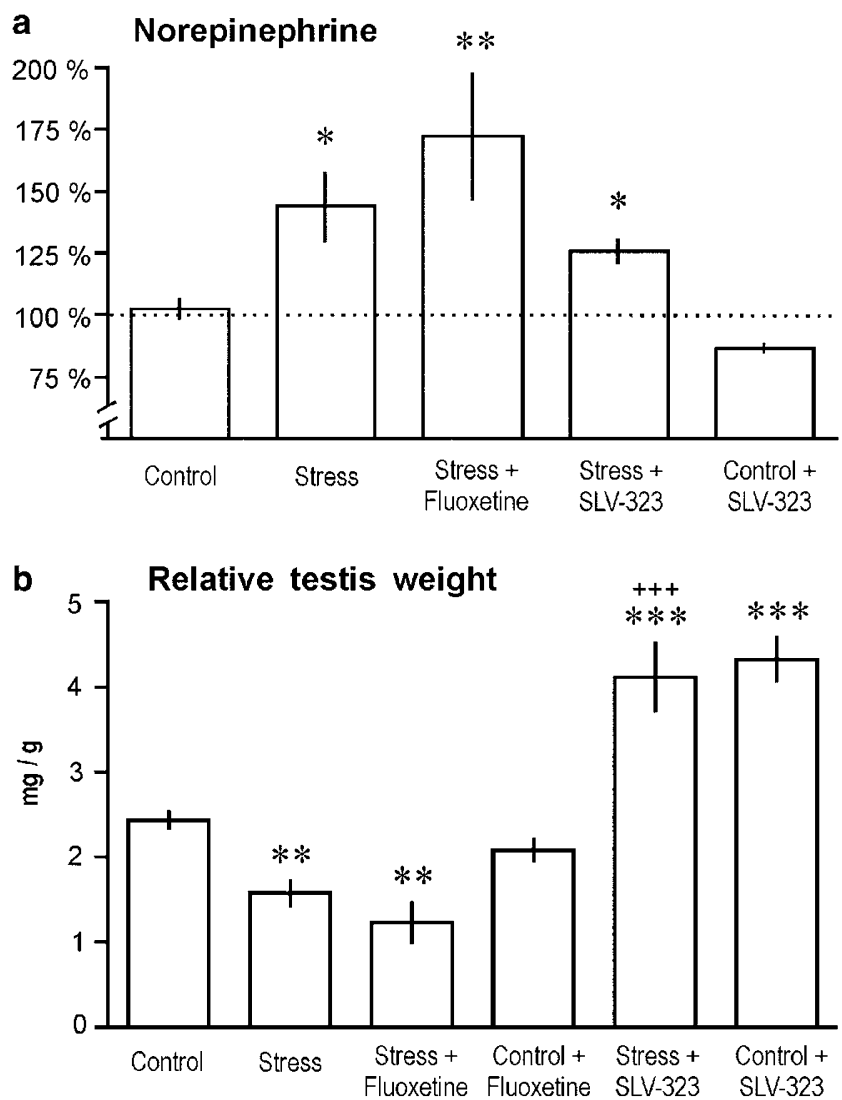

Figure 3 (a) Concentration of urinary norepinephrine. Long-term stress resulted in the sustained activation of the sympatho-adrenomedullary system, as indicated by the significant elevation of urinary norepinephrine levels in all stressed groups after the 5 weeks of social encounters. Horizontal dashed line indicates the mean baseline urinary norepinephrine excretion according to the measurement during the Pre-Stress week. Data are expressed as percent of the Pre-Stress week. (b) Effects of chronic psychosocial stress and concomitant drug treatment on testis weight. Longterm stress resulted in a significantly reduced relative testis weight in the animals from the Stress and Stress + Fluoxetine groups, while treatment with the $N K_{1} R$ antagonist SLV-323 significantly increased the weight of the organ. Note that SLV-323 treatment resulted in significantly increased testis weight both in control and stressed animals. Data are expressed as mg testis weight per $g$ average body weight of the last week (mean \pm SEM). Statistics: One-way ANOVA followed by Student-Newman-Keuls post hoc analysis. ${ }^{*}<0.05$, *** $<0.0$ I, ***** $<0.00$ I vs Control; $+++<0.00$ I vs Stress. 

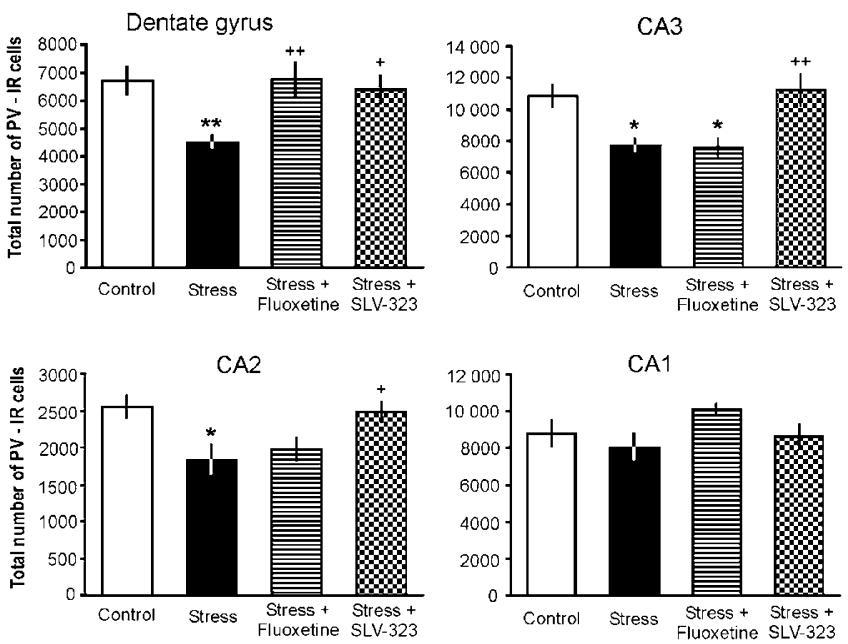

Figure 4 Effects of chronic psychosocial stress and concomitant antidepressant drug treatment on the total number of parvalbuminimmunoreactive (PV-IR) cells in the different hippocampal subregions. Stress significantly decreased the number of PV-IR cells in the dentate gyrus, $C A 2$, and CA3, whereas the CAI was not affected. The NK, R antagonist SLV-323 prevented the stress-induced effect in all hippocampal subregions, whereas fluoxetine had a beneficial effect in the dentate gyrus, but not in the CA2 and CA 3 subfields. Results are shown as mean \pm SEM. Importantly, because comparison of the results of the two Stress groups from the first and second experiment (Figure I) did not reveal a statistically significant difference, their values were combined and presented here as one group. Statistics: one-way ANOVA, followed by Tukey's post hoc analysis. $* 0.05$, *** $<0.0$ I vs Control; $+<0.05,++<0.0$ I vs Stress.

$\left(-29 \%, t_{17}=3.43, p<0.01\right.$; Table 1$)$. A minor, nonsignificant difference $(-9 \%)$ was observed in the total number of PV-positive cells in the CA1 area (Table 1). In the CA2 area, total PV-IR interneuron numbers were also significantly decreased $\left(-28 \%, t_{17}=2.85, p<0.05\right.$; Stress: $1833 \pm 218$ PVIR cells) compared with the unstressed controls (Control: $2547 \pm 162$ PV-IR cells) (Figure 4). Importantly, because there was no statistical difference between the two Stress groups from the first and second experiment, their values were pooled, and presented here as one group.

The second experiment was designed to examine whether the chronic stress-induced decrease in the number of PV-IR interneurons was blocked by concomitant application of antidepressant drugs (Figure 4). Cell quantification revealed that treatment with both fluoxetine and the $\mathrm{NK}_{1} \mathrm{R}$ antagonist prevented the effect of stress in the DG (Table 1). One-way ANOVA revealed a significant difference between the groups $\left(\mathrm{F}_{(3,24)}=6.84, p<0.01\right)$ and Tukey's post hoc comparisons showed a significant difference between the Control and Stress groups $(q=5.05, p<0.01)$. Treatment of stressed animals with the $\mathrm{NK}_{1} \mathrm{R}$ antagonist SLV-323 offered protection from the effect of stress, resulting in the preservation of PV-IR interneurons and a statistically significant difference compared with the Stress group $(q=4.36, p<0.05)$. A similar effect was observed in animals from the Stress + Fluoxetine group $(q=4.89, p=0.01 v s$ Stress), whereas values of the two drug-treated groups were similar to those for the Controls.

Analysis of the CA3 area revealed that administration of the $\mathrm{NK}_{1} \mathrm{R}$ antagonist prevented the stress-induced changes, whereas fluoxetine treatment presently had no beneficial effect (Table 1). One-way ANOVA revealed a significant difference between the groups $\left(\mathrm{F}_{(3,24)}=6.93, p=0.01\right)$ and post hoc comparisons showed significant difference between the Control and Stress groups $(q=4.50, p<0.05)$. Treatment of stressed animals with the $\mathrm{NK}_{1} \mathrm{R}$ antagonist SLV-323 resulted in normalization of the total number of PV-IR interneurons, yielding a significant difference compared with the Stress group $(q=5.07, p=0.01)$. In contrast, results of the Stress + Fluoxetine group did not differ from the Stress group; however, the total number of PV-IR interneurons was significantly lower than in the Control group $(q=3.91, p<0.05)$.

In the CA2 subregion, chronic treatment with the $\mathrm{NK}_{1} \mathrm{R}$ antagonist resulted in a normalized total number of PV-IR cells (Stress $+N K_{1} R$ antagonist: $2480 \pm 140$ PV-IR cells), indicating that SLV-323 counteracted the effect of stress $(q=4.01, p<0.05$ vs Stress). In contrast, results of the Stress + Fluoxetine $(1974 \pm 175$ PV-IR neurons) were in the same range as those from the Stress group; statistically, however, they were not different from either the Control or the Stress group (Figure 4).

In the CA1 subregion of the Ammon's horn, neither stress nor antidepressant treatment had a significant effect on the number of PV-labeled neurons (ANOVA $\left(\mathrm{F}_{(3,24)}=1.63\right.$, $p=0.21$ ), Table 1).

Using the experimental parameters for the optical fractionator that were established during a pilot experiment, the average number of counted neurons varied between 197 and 582 in the DG, between 334 and 965 in the CA3, and between 389 and 860 in the CA1, which is well beyond the recommendation of Gundersen and Jensen (1987). Furthermore, according to the rules of the optical fractionator technique, to make justified group comparisons, the biological variance $\left(\mathrm{BCV}^{2}\right)$ should contribute more than $50 \%$ to the total observed variance $\left(\mathrm{CV}^{2}\right)$, where $\mathrm{CV}^{2}=\mathrm{CE}^{2}$ $+\mathrm{BCV}^{2}$ (Gundersen, 1986). As shown in Table 1, our stereological sampling fulfilled this criterion in all cases, except in the CA1 region of the Stress + Fluoxetine group, where the biological variance was unusually low.

The third experiment was designed to test whether treatment of unchallenged animals with the two compounds might affect the number of parvalbumin-IR cells. As shown in Figure 5, neither fluoxetine nor SLV-323 influenced the number of hippocampal PV-IR interneurons.

Finally, we evaluated whether using higher titers of the primary antibody might pick up cells that express lower levels of parvalbumin. For that, we selected four animals of the Stress group, which had the lowest number of PV-IR cells, and processed three series of every tenth serial sections for immunohistochemistry with different titers of the primary antibody (ie $1: 1000,1: 2000,1: 3000$ ). Quantification of the parvalbumin-positive cells revealed that different titers of the primary antibody had no effect on the incidence of labeled cells (data not shown).

\section{DISCUSSION}

The present study is the first to quantify the absolute number parvalbumin-immunoreactive interneurons in the hippocampal formation; furthermore, this is the first observation showing that long-term psychosocial stress 
Table I Stereological Results: Mean Estimated Total PV-IR Interneuron Numbers in the Three Major Hippocampal Subregions after Chronic Psychosocial Stress and Concomitant Antidepressant Treatment with Fluoxetine or SLV-323, a Novel NK, Receptor Antagonist

\begin{tabular}{|c|c|c|c|c|}
\hline & Control & Stress $^{a}$ & Stress+Fluoxetine & Stress+SLV-323 \\
\hline \multicolumn{5}{|l|}{ Dentate Gyrus } \\
\hline Mean N & 6700 & $4475^{* *}$ & $6762^{\# \#}$ & $6393^{\#}$ \\
\hline Mean CE & 0.082 & 0.137 & 0.089 & 0.059 \\
\hline SD & 1298 & 1033 & 1436 & 1323 \\
\hline $\mathrm{CV}=\mathrm{SD} /$ mean & 0.1937 & 0.2307 & 0.2123 & 0.2069 \\
\hline \multicolumn{5}{|l|}{ Hippocampal CA3 } \\
\hline Mean N & 10848 & $7696 *$ & $7575 *$ & $11248^{\# \#}$ \\
\hline Mean CE & 0.057 & 0.080 & 0.079 & 0.059 \\
\hline SD & 1822 & 1802 & 1388 & 2634 \\
\hline Mean N & 8778 & 8004 & 10104 & 8615 \\
\hline Mean CE & 0.069 & 0.076 & 0.058 & 0.069 \\
\hline SD & 1886 & 2003 & 757 & 1697 \\
\hline $\mathrm{CV}=\mathrm{SD} /$ mean & 0.2148 & 0.2503 & 0.0749 & 0.1970 \\
\hline$B C V^{2}$ (in $\%$ of $C V^{2}$ ) & $90 \%$ & $91 \%$ & $40 \%$ & $79 \%$ \\
\hline
\end{tabular}

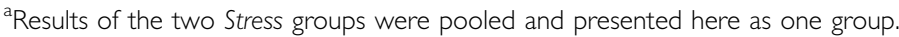

$\mathrm{CE}$, coefficient of error, mean CE was calculated $\sqrt{\text { mean }(C E)^{2}} ; \mathrm{SD}$, standard deviation; $\mathrm{BCV}$, biological variance, where $C V^{2}=C E^{2}+B C V^{2}$.

Statistics: one-way ANOVA, followed by Tukeýs post hoc analysis.

$*<0.05$, $* *$ * $<0.0$ I vs Control; \#<0.05, \#\#<0.01 vs Stress.
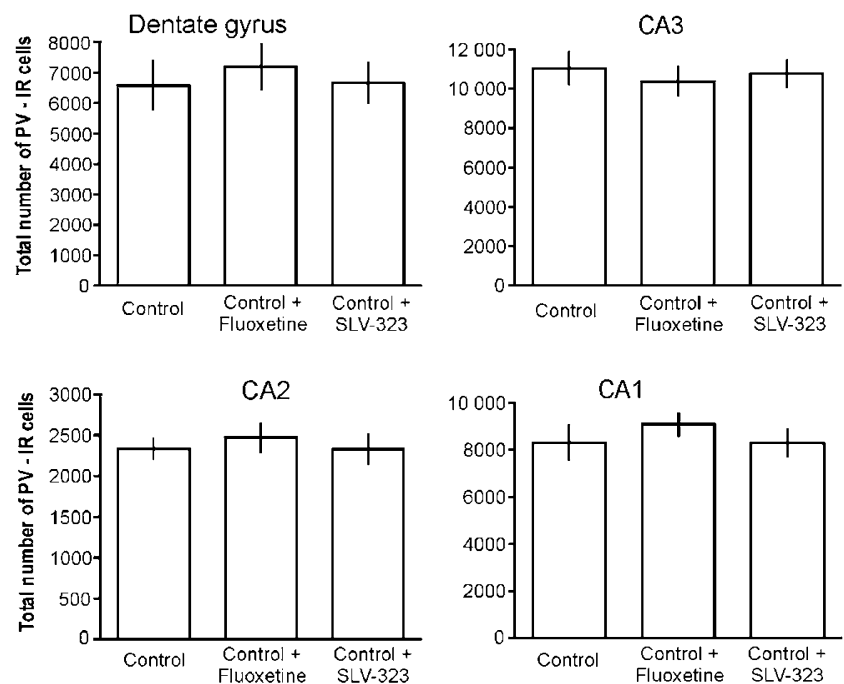

Figure 5 Chronic treatment with fluoxetine or the $N K_{1} R$ antagonist SLV-323 did not affect the total number of parvalbumin-IR neurons in the hippocampi of control animals. Results are presented as mean \pm SEM.

may affect the number of nonprincipal cells in the hippocampus. We demonstrated that chronic psychosocial stress resulted in a significantly fewer PV-IR cells in the DG and in the CA2 and CA3 regions of the Ammon's horn, whereas the CA1 subfield was not affected. Additionally, we found that this effect of long-term stress was prevented by concomitant treatment with the $\mathrm{NK}_{1}$ receptor antagonist SLV-323. Treatment with fluoxetine partially counteracted the stress-induced changes: it normalized the number of PV-IR interneurons in the DG, but had no effect in the CA2 and CA3 areas. This suggests that antidepressant drugs directly or indirectly modulate the hippocampal GABAergic network. Furthermore, we demonstrated that, in this context, blockade of $\mathrm{NK}_{1}$ receptors with the selective antagonist SLV-323 had a similar, or even a better, protective profile than the established antidepressant fluoxetine. SLV-323 treatment had a further interesting effect on the periphery; namely, it blocked the stressinduced decrease of testis weight. In this respect, SLV-323 may devoid the common and unwanted side effect of many SSRIs, namely sexual dysfunction.

\section{Effect of Stress on the Hippocampal GABAergic System}

To our knowledge, this is the first report demonstrating that the number of hippocampal parvalbumin-containing GABAergic interneurons is modulated by long-term stress and antidepressant treatment, and our data thereby provide further support for theories that link stress or depression with epilepsy (Magarinos et al, 1997; Kanner and Balaba- 
nov, 2002). Disturbances in the anatomy and function of the GABAergic system have been implicated in connection with various stress-related psychiatric disorders (Sanacora et al, 1999; Benes and Berretta, 2001; Krystal et al, 2002; Brambilla et al, 2003). Changes in the number of local inhibitory neurons have been reported, especially in the anterior cingulate and prefrontal cortices, and in the hippocampi of schizophrenic and bipolar patients (Benes, 1999; Benes and Berretta, 2001; Reynolds et al, 2001; Beasley et al, 2002; Cotter et al, 2002). These observations are often interpreted as a consequence of altered neurodevelopment, but the contribution of stressful experiences, especially in the perinatal period, should be also taken into account (Vaid et al, 1997; Benes et al, 1998). A recent post-mortem study comparing densities of different subpopulations of GABAergic interneurons revealed a significant and profound deficit in the relative density of PV-immunoreactive neurons in all hippocampal subfields of schizophrenic patients, but they did not reveal any changes in patients with a depressive disorder (Zhang and Reynolds, 2002). Another post-mortem study evaluating the density of hippocampal nonprincipal neurons in Nissl stained sections found significantly decreased density of interneurons in the CA2 subregion of both schizophrenic and bipolar subjects (Benes et al, 1998). Furthermore, in both disorders, the number of nonprincipal cells was substantially decreased in the CA3 area, approaching the level of significance, whereas the CA1 was not affected (the DG was not analyzed) (Benes et al, 1998). As the authors pointed out, this histopathological change seems to be related more to an environmental factor such as stress, which occurs to an equivalent extent in both disorders, as this decrease of interneuron number in the hippocampus and elsewhere in the cortex appears to be a feature of both schizophrenia and bipolar disorder (Benes et al, 1998).

There are many reports of chronic stress-induced structural alterations within the hippocampal formation, including remodeling of the apical dendrites of CA3 pyramidal cells (Magarinos et al, 1996; Kole et al, 2004), suppression of adult neurogenesis in the DG (Czéh et al, 2002; Pham et al, 2003) and reduced hippocampal volume (van der Hart et al, 2002). The CA3 pyramidal cells are considered especially vulnerable to excitotoxic injury (McEwen, 1999) because they are subjected to the elevated excitatory amino-acid release from the mossy fiber terminals (Magarinos et al, 1997). As PV-containing interneurons receive similarly robust, or probably an even stronger, excitatory input from the mossy fibers (Acsady et al, 1998; Seress et al, 2001), one may assume that they might eventually die from excitotoxic injury, similar to that following epileptic seizures (Buckmaster and Dudek, 1997). Our group examined the possibility of cell loss within the same chronic psychosocial paradigm, but stereological cell counting of pyramidal and granule cells of the hippocampal formation failed to reveal any loss of cells (Vollmann-Honsdorf et al, 1997; Sousa et al, 1998; Keuker et al, 2001). It should be noted though that possible changes in the number of interneurons or hilar cells were not specifically addressed in these studies. Recently, we also quantified the incidence of apoptosis in this chronic stress paradigm, and we found a significant increase in the number of apoptotic cells in the hilus and a nonsignificant increase in the granule cell layer, whereas in the CA3 the occurrence of apoptosis was decreased (Lucassen et al, 2001). Considering the results of apoptotic cell number, excitotoxic cell death may explain the decreased number of $\mathrm{PV}$-containing interneurons in the dentate hilus, but it conflicts with the present data observed in the CA3 area. Altogether, we cannot rule out the possibility that long-term stress may induce excitotoxic interneuron loss.

More importantly, our data indicate that this effect of stress can be prevented by antidepressant treatment. The fact that the number of parvalbumin-containing hippocampal interneurons were not increased by treatment with either of fluoxetine or the SLV-323 in the control animals suggest that the effect of stress were blocked by the drug treatments and not vice versa. Currently, antidepressants are believed to exert their primary biochemical effects by readjusting aberrant intrasynaptic concentrations of serotonin and norepinephrine. However, a rapidly growing number of clinical and preclinical studies indicate that major depressive disorders may be associated with an impairment of structural plasticity and cellular resilience, and that antidepressant medications may act by correcting this dysfunction (Duman et al, 1999; Manji et al, 2000, 2001, 2003). Recent preclinical data suggest that the common cellular mechanism underlying the effects of different types of antidepressant compounds may be their neurotrophic/ neuroprotective properties, which are mediated by different neurotrophic signaling cascades (most notably cyclic adenosine monophosphate (cAMP) response element binding (CREB) protein, brain-derived neurotrophic factor (BDNF), bcl-2, and mitogen-activated protein (MAP) kinases) (Duman et al, 1999; Manji et al, 2000, 2001, 2003). Furthermore, there is clinical evidence to suggest that antidepressant treatment may increase BDNF levels in human brain (Chen et al, 2001) and can protect against hippocampal volume loss in human patients (Sheline et al, 2003). Suppose, the reduced number of PV-positive neurons we observed in stressed animals is indicative for cell death, one might suggest that fluoxetine or SLV-323 treatment could protect against excitotoxic cell loss. Indeed, we recently demonstrated in the same experimental paradigm that treatment with the antidepressant tianeptine can protect against neural cell death (Lucassen et al, 2004).

Another possible explanation for our results is that, because of the stress insult, the perikaryal PV content falls bellow levels detectable by immunohistochemistry, this might be the case even though processing sections with a much higher concentrations of the primary antibody could not label more parvalbumin-IR cells. A reduction of such a calcium-buffering system within the cells may potentially reflect a functional impairment of the PV-containing interneurons, but it could also be a compensatory mechanism (see below). There is experimental evidence that, in animals subjected to either acute or chronic stress, the expression of the GABA synthesizing enzyme GAD67 mRNA is significantly enhanced within the hippocampal formation (Bowers et al, 1998). Notably, after 2 weeks of stress, the most pronounced increase of GAD67 mRNA expression was detected in the DG and CA3 region (Bowers et al, 1998), and the same subregions were affected in our experiment. Very similar results were observed after combination of pre- and postnatal corticosterone exposure: 
5 days after the final corticosterone treatment, GAD67 mRNA expression was increased in the cells located on the border of the hilus and granule cell layer, in the stratum pyramidale of $\mathrm{CA} 3$, and in the stratum oriens and pyramidale of the CA1 (Stone et al, 2001); these are the areas where basket and chandelier cells are located most densely. The authors pointed out a remarkable fact that the largest increase (two-fold) in GAD mRNA expression was found in the GABAergic basket cells of the DG, whereas GAD mRNA expression was not altered in adjacent GABAergic interneurons projecting to the granule cell dendrites (Stone et al, 2001). Increased GAD67 mRNA expression may reflect a general cellular response to injury; alternatively, it may indicate a compensatory attempt to increase the production and release of GABA, which in turn would suppress neuronal firing within the overexcited circuits. Similar explanations may account for the alterations of parvalbumin content within the cells.

The exact physiological role of the calcium-binding protein parvalbumin is not yet clear, but results of studies on PV-deficient mice show that low levels of parvalbumin in the axon terminals result in increased GABA release, so PV is likely to modulate the $\mathrm{Ca}^{2+}$-dependent release of GABA (Vreugdenhil et al, 2003). It has also been demonstrated that, after repeated seizures, the density of hippocampal $\mathrm{PV}$-immunoreactive neurons rapidly decreases, without changing the density of GABA-immunoreactive neurons in the same area. This indicates that in response to seizure activity, the perikaryal PV content falls below levels detectable by immunohistochemistry (Scotti et al, 1997). A reduction of such a calcium-buffering system within the cells may potentially reflect a functional impairment of the $\mathrm{PV}$-containing basket and chandelier cells, but it might also be a compensatory mechanism. Hypothetically, this might reflect a kind of plastic change; perisomatic inhibitory cells might be able to downregulate their parvalbumin content to facilitate GABA release. Such an adaptive change may help the GABA system prevent excessive firing of the principal cells caused by either repeated stress or epileptic seizures. This explanation may resolve the seemingly controversial observations of decreased numbers of PV-IR cells (present data) and enhanced expression of GAD67 mRNA levels after chronic stress (Bowers et al, 1998) or repeated corticosterone treatment (Stone et al, 2001). Moreover, this may also explain the observation that in vivo high-frequency stimulation of the mossy fiber inputs to CA3 produced epileptic after-discharges in $56 \%$ of acutely stressed animals, whereas this happened in only $29 \%$ of chronically stressed animals (Pavlides et al, 2002). Of course, we cannot exclude another possibility, namely that the remaining GABA neurons upregulate their GAD production to compensate the loss of their vulnerable subpopulation (Esclapez and Houser, 1999).

\section{Antidepressant Treatment can Counteract the Effect of Stress}

Remarkably, the above-mentioned chronic stress-induced enhancement of GAD67 mRNA expression in the hippocampus can be blocked by treatment with an antidepressant, the highly selective norepinephrine reuptake inhibitor reboxetine (Herman et al, 2003). In our experiment, treatment with fluoxetine, a serotonin (5-HT) selective reuptake inhibitor (SSRI) with well-known clinical efficacy (Stokes and Holtz, 1997) prevented the chronic stressinduced effect. The serotonergic innervation of the hippocampus originates from the dorsal and median raphe nuclei, but only $21 \%$ of serotonin-containing varicosities make synaptic contacts, mostly with dendrites and somata of GABAergic interneurons, and it has been suggested that those varicosities without synaptic contact release 5-HT at nonsynaptic sites for long distance diffusion (Vizi and Kiss, 1998). Experimental serotonin treatment hyperpolarizes both pyramidal and granule cells, with the effect possibly occurring directly on principal cells, or mediated by excitation of interneurons (Freund and Buzsaki, 1996). Accordingly, treatment with the SSRI fluoxetine can lead to a general inhibition of hippocampal network activity and, indeed, animal experiments suggest that SSRIs at therapeutic doses are able to decrease seizure susceptibility of the hippocampus (Wada et al, 1995; Hernandez et al, 2002). Thus, in our case, fluoxetine treatment may provide sufficient counterbalancing inhibition to the overexcited hippocampal circuitry, and thereby prevent the compensatory downregulation of parvalbumin to enhance GABA release. Alternatively, the beneficial effect of fluoxetine treatment could be explained by its potential neurotrophic/ neuroprotective properties, which results in an enhancement of neuronal viability.

\section{The Effect of the $\mathrm{NK}_{1}$ Receptor Antagonist}

In the present study, in addition to fluoxetine, we used the $\mathrm{NK}_{1}$ receptor antagonist SLV-323 (Czeh et al, 2003; Hesselink et al, 2003), because inhibition of substance P and its preferred $\mathrm{NK}_{1} \mathrm{R}$ pathway is a promising novel approach to antidepressant treatment (Rupniak and Kramer, 1999; Stout et al, 2001). Functional studies indicate that pharmacological blockade or deletion of the $\mathrm{NK}_{1} \mathrm{R}$ might be as effective as currently used antidepressants in the suppression of psychological and behavioral stress responses (Rupniak, 2002). In humans, the first clinical study using an $\mathrm{NK}_{1} \mathrm{R}$ antagonist for the treatment of depression reported promising results regarding the therapeutic efficacy of an $\mathrm{NK}_{1} \mathrm{R}$ antagonist (Kramer et al, 1998, 2004). It has been suggested that the potential therapeutic effects of $\mathrm{NK}_{1} \mathrm{R}$ antagonists are mediated via the dorsal raphe nucleus, a major source of forebrain serotonin that has been implicated in affective disorders. According to this explanation, treatment with an $\mathrm{NK}_{1}$ receptor antagonist treatment results in desensitization of the autoinhibitory $5-\mathrm{HT}_{1 \mathrm{~A}}$ receptor and enhanced serotonergic neurotransmission (Santarelli et al, 2001). However, it should be noted that, in rats treated with the $\mathrm{NK}_{1}$ antagonist GR205171, the efflux of 5-HT in the hippocampus was not increased (Millan et al, 2001).

Administration of an $\mathrm{NK}_{1} \mathrm{R}$ antagonist is likely to exert an effect directly on hippocampal neurons. Nevertheless, the exact physiological role of substance $\mathrm{P}$ in the hippocampus is still disputed, partly because of a general mismatch between the extent of fibers containing substance $\mathrm{P}$ and the quantity of $\mathrm{NK}_{1}$ receptors (Nakaya et al, 1994; Ribeiroda-Silva and Hökfelt, 2000). Anatomical data indicate that, in the hippocampal formation, the highest density of 
immunoreactive substance $P$ receptors is present on GABAergic inhibitory interneurons, including PV-containing cells (Sloviter et al, 2001). It is possible that in the hippocampus, as in other CNS areas, substance $\mathrm{P}$ may be reaching its target receptors via nonsynaptic diffusion (Mantyh et al, 1995). Diffusion of substance $P$ from its release sites onto dentate granule cells thus may provide a strong excitatory influence on these cells, by prolonging the time that the NMDA channel spends in the open state (Lieberman and Mody, 1998). As granule cells of the DG are thought to gate the amount of excitatory input to the hippocampus, administering an $\mathrm{NK}_{1} \mathrm{R}$ antagonist may result in an overall suppression of hippocampal network activity and, indeed, $\mathrm{NK}_{1} \mathrm{R}$ antagonists are suggested to constitute a novel category of drugs in antiepileptic therapy (Liu et al, 1999). Therefore, similarly to fluoxetine treatment, SLV-323 may supply a sufficient amount of compensatory inhibition to prevent the excessive firing of the principal cells, so the downregulation of parvalbumin is not necessary. Alternatively, the protective effect of SLV-323 could be due to its potential neurotrophic/neuroprotective properties.

\section{Stress and Antidepressant Treatment can Affect Adult Hippocampal Neurogenesis}

Another remarkable feature of PV-positive interneurons has been demonstrated recently - about $14 \%$ of newly generated neurons in the adult DG are apparently GABAergic parvalbumin-positive cells (Liu et al, 2003). This is especially interesting in light of the fact that both acute and chronic stress can affect the production of new neurons in the dentate subgranular zone by suppressing both the proliferation rate of precursors and the survival rate of the daughter cells (Gould et al, 1997; Czeh et al, 2001, 2002; Pham et al, 2003). Furthermore, this stress-induced suppression of cytogenesis is counteracted by various classes of antidepressant drug treatment, including $\mathrm{NK}_{1} \mathrm{R}$ antagonists (Czeh et al, 2001; van der Hart et al, 2002; Malberg and Duman, 2003). This form of neuroplasticity may provide an alternative explanation to our present observations. Accordingly, in the DG the reduced number of PV-IR interneurons may be a consequence of the stressinduced suppression of adult neurogenesis, whereas the neurotrophic effect of antidepressant treatment could normalize the number of PV-containing cells. However, this explanation cannot account for the alterations observed in the CA2 and CA3 regions.

\section{Methodical Considerations}

To our knowledge, the present study is the first that quantified the total number of PV-positive cells in the hippocampus; thus, no comparison to other results from any species is available. It may appear that the number of PV-IR cells are extraordinarily low, but it should be emphasized that the number of nonprincipal neurons in the hippocampus is about 10-20 times smaller than of principal cells (Freund and Buzsaki, 1996; Benes et al, 1998). Furthermore, immunohistochemistry staining using the parvalbumin antibody visualizes only a fraction $(\sim 20-$ $40 \%$ ) of all GABAergic neurons in the hippocampus (Freund and Buzsaki, 1996).
Due to their low number, quantifying hippocampal interneurons using the unbiased stereological technique is challenging (Benes et al, 1998). To be able to fulfill the requirements of the stereological approach, we had to exclude certain hippocampal layers from the analysis, where the occurrence of PV-containing neurons is extremely low. Furthermore, we applied the modified optical disector method, which could have caused a potential bias. In contrast to the unbiased optical disector technique, we did not use guard zones at the top and bottom of the section. However, results from studies working similarly to us on $50 \mu \mathrm{m}$ cryosections suggest that the outcome of the unbiased and the modified optical disector approach is the same (Harding et al, 1994; Keuker et al, 2004). Altogether, the presented values here may not precisely reflect the absolute number of PV-containing interneurons in the tree shrew hippocampal formation, but given the fact that we applied the same cell counting protocol for each group, it is very unlikely that the observed group differences are artifacts due to any potential biases caused by the method.

\section{CONCLUSION}

In summary, long-term stress results in a decreased number of PV-containing GABAergic interneurons in the hippocampal formation. This may indicate either a real excitotoxic cell loss or that the intracellular parvalbumin content is reduced below levels detectable by the immunocytochemical method. A reduction of such a calcium-buffering system within the cells may reflect a functional impairment of the basket and chandelier cells. Alternatively, it could hypothetically be a kind of compensatory mechanism, a form of neuroplasticity, to facilitate GABA release, as an attempt to counterbalance the enhanced excitatory activity of the principal cells caused by repeated stress. Importantly, concomitant antidepressant treatment prevented the effect of stress either by enhancing neuronal viability or probably by providing sufficient compensatory inhibition to the overexcited hippocampal circuitry, so the downregulation of the calcium-buffering parvalbumin is prevented by the drug treatment. Notably, neither fluoxetine nor the SLV-323 had any effect on the number of parvalbumin-containing hippocampal interneurons in control animals. Furthermore, we demonstrated that, in this experimental setting, the $\mathrm{NK}_{1} \mathrm{R}$ antagonist SLV-323 showed even greater neurobiological efficacy than fluoxetine.

\section{ACKNOWLEDGEMENTS}

The presented study has been partially supported by Solvay Pharmaceuticals, Weesp, The Netherlands and GlaxoSmithKline, Verona, Italy. We are grateful to JI Keuker and MHP Kole for the stimulating discussions and for critically reading the manuscript. We thank Professor $\mathrm{C}$ Hiemke for determining fluoxetine plasma concentrations, and $S$ Donath and A Heutz for their excellent technical assistance. Analysis of urine levels of norepinephrine and creatinine was performed at KCL Bioanalysis b.v., Leeuwarden, The Netherlands. We thank Jan Berk for his help. 


\section{REFERENCES}

Acsady L, Kamondi A, Sik A, Freund T, Buzsaki G (1998). GABAergic cells are the major postsynaptic targets of mossy fibers in the rat hippocampus. J Neurosci 18: 3386-3403.

Beasley CL, Zhang ZJ, Patten I, Reynolds GP (2002). Selective deficits in prefrontal cortical GABAergic neurons in schizophrenia defined by the presence of calcium-binding proteins. Biol Psychiatry 52: 708-715.

Benes FM (1999). Evidence for altered trisynaptic circuitry in schizophrenic hippocampus. Biol Psychiatry 46: 589-599.

Benes FM, Berretta S (2001). GABAergic interneurons: implications for understanding schizophrenia and bipolar disorder. Neuropsychopharmacology 25: 1-27.

Benes FM, Kwok EW, Vincent SL, Todtenkopf MS (1998). A reduction of nonpyramidal cells in sector CA2 of schizophrenics and manic depressives. Biol Psychiatry 44: 88-97.

Bowers G, Cullinan WE, Herman JP (1998). Region-specific regulation of glutamic acid decarboxylase (GAD) mRNA expression in central stress circuits. J Neurosci 18: 5938-5947.

Brambilla P, Perez J, Barale F, Schettini G, Soares JC (2003). GABAergic dysfunction in mood disorders. Mol Psychiatry 8: 721-737 715.

Bremner JD (2002). Neuroimaging studies in post-traumatic stress disorder. Curr Psychiatry Rep 4: 254-263.

Buckmaster PS, Dudek FE (1997). Neuron loss, granule cell axon reorganization, and functional changes in the dentate gyrus of epileptic kainate-treated rats. J Comp Neurol 385: 385-404.

Chen B, Dowlatshahi D, MacQueen GM, Wang JF, Young LT (2001). Increased hippocampal BDNF immunoreactivity in subjects treated with antidepressant medication. Biol Psychiatry 50: 260-265.

Cotter D, Landau S, Beasley C, Stevenson R, Chana G, MacMillan L et al (2002). The density and spatial distribution of GABAergic neurons, labelled using calcium binding proteins, in the anterior cingulate cortex in major depressive disorder, bipolar disorder, and schizophrenia. Biol Psychiatry 51: 377-386.

Czeh B, Michaelis T, Watanabe T, Frahm J, de Biurrun G, van Kampen $\mathrm{M}$ et al (2001). Stress-induced changes in cerebral metabolites, hippocampal volume, and cell proliferation are prevented by antidepressant treatment with tianeptine. Proc Natl Acad Sci USA 98: 12796-12801.

Czeh B, van der Hart MGC, Pudovkina O, Fuchs E (2003). Stressinduced alterations in neuroendocrine and behavioral parameters, dentate cell proliferation and hippocampal volume are prevented by the NK1 receptor antagonist SLV-323. Society for Neuroscience Abstracts, Program No. 849.1.

Czeh B, Welt T, Fischer AK, Erhardt A, Schmitt W, Muller MB et al (2002). Chronic psychosocial stress and concomitant repetitive transcranial magnetic stimulation: effects on stress hormone levels and adult hippocampal neurogenesis. Biol Psychiatry 52: 1057-1065.

Duman RS, Malberg J, Thome J (1999). Neural plasticity to stress and antidepressant treatment. Biol Psychiatry 46: 1181-1191.

Esclapez M, Houser CR (1999). Up-regulation of GAD65 and GAD67 in remaining hippocampal GABA neurons in a model of temporal lobe epilepsy. J Comp Neurol 412: 488-505.

Fischer HD, Heinzeller T, Raab A (1985). Gonadal response to psychosocial stress in male tree shrews (Tupaia belangeri) morphometry of testis, epididymis and prostate. Andrologia 17: 262-275.

Freund TF, Buzsaki G (1996). Interneurons of the hippocampus. Hippocampus 6: 347-470.

Fuchs E (1999). Tree shrews. In: Poole T (ed). UFAW Handbook on the Care and Management of Laboratory Animals, 7th edn. Blackwell: Oxford, UK. pp 235-245.

Fuchs E, Flugge G (2002). Social stress in tree shrews: effects on physiology, brain function, and behavior of subordinate individuals. Pharmacol Biochem Behav 73: 247-258.
Fukuda T, Kosaka T (2000). Gap junctions linking the dendritic network of GABAergic interneurons in the hippocampus. J Neurosi 20: 1519-1528.

Gould E, McEwen BS, Tanapat P, Galea LA, Fuchs E (1997). Neurogenesis in the dentate gyrus of the adult tree shrew is regulated by psychosocial stress and NMDA receptor activation. J Neurosci 17: 2492-2498.

Gundersen HJ (1986). Stereology of arbitrary particles. A review of unbiased number and size estimators and the presentation of some new ones, in memory of William R Thompson. J Microsc 143: 3-45.

Gundersen HJ, Bagger P, Bendtsen TF, Evans SM, Korbo L, Marcussen $\mathrm{N}$ et al (1988). The new stereological tools: disector, fractionator, nucleator and point sampled intercepts and their use in pathological research and diagnosis. APMIS 96: 857-881.

Gundersen HJ, Jensen EB (1987). The efficiency of systematic sampling in stereology and its prediction. J Microsc 147: 229-263.

Harding AJ, Halliday GM, Cullen K (1994). Practical considerations for the use of the optical disector in estimating neuronal number. J Neurosci Methods 51: 83-89.

Herman JP, Renda A, Bodie B (2003). Norepinephrine-gammaaminobutyric acid (GABA) interaction in limbic stress circuits: effects of reboxetine on GABAergic neurons. Biol Psychiatry 53: $166-174$.

Hernandez EJ, Williams PA, Dudek FE (2002). Effects of fluoxetine and TFMPP on spontaneous seizures in rats with pilocarpineinduced epilepsy. Epilepsia 43: 1337-1345.

Hesselink MB, Tuinstra T, Dijksman J, McCreary A, van Stuivenberg H, Adolfs $\mathrm{T}$ et al (2003). Pharmacological characterisation of SLV-323, a novel CNS-active NK1 antagonist. Society for Neuroscience Abstracts, Program No. 539.1.

Kanner AM, Balabanov A (2002). Depression and epilepsy: how closely related are they? Neurology 58(Suppl 5): S27-S39.

Keuker JIH, de Biurrun G, Luiten PGM, Fuchs E (2004). Preservation of hippocampal neuron numbers and hippocampal subfield volumes in behaviorally characterized aged tree shrews. J Comp Neurology 468: 509-517.

Keuker JIH, Rochford CDP, Witter MP, Fuchs E (2003). A cytoarchitectonic study of the hippocampal formation of the tree shrew (Tupaia belangeri). J Chem Neuroanat 26: 1-15.

Keuker JIH, Vollmann-Honsdorf GK, Fuchs E (2001). How to use the optical fractionator: an example based on the estimation of neurons in the hippocampal CA1 and CA3 regions of tree shrews. Brain Res Protocols 7: 211-221.

Kole MHP, Czeh B, Fuchs E (2004). Homeostatic maintenance in excitability of tree shrew hippocampal CA3 pyramidal neurons after chronic stress. Hippocampus 14: 742-751.

Kosaka T, Katsumaru H, Hama K, Wu J-Y, Heizmann CW (1987). GABAergic neurons containing the $\mathrm{Ca}^{2+}$-binding protein parvalbumin in the rat hippocampus and dentate gyrus. Brain Res 419: 119-130.

Kramer MS, Cutler N, Feighner J, Shrivastava R, Carman J, Sramek JJ et al (1998). Distinct mechanism for antidepressant activity by blockade of central substance $\mathrm{P}$ receptors. Science 281: 1640-1645.

Kramer MS, Winokur A, Kelsey J, Preskorn SH, Rothschild AJ, Snavely D et al (2004). Demonstration of the efficacy and safety of a novel substance $\mathrm{P}$ (NK1) receptor antagonist in major depression. Neuropsychopharmacology 29: 385-392.

Krystal JH, Sanacora G, Blumberg H, Anand A, Charney DS, Marek $\mathrm{G}$ et al (2002). Glutamate and GABA systems as targets for novel antidepressant and mood-stabilizing treatments. Mol Psychiatry 7: S71-S80.

Lieberman DN, Mody I (1998). Substance P enhances NMDA channel function in hippocampal dentate gyrus granule cells. J Neurophysiol 80: 113-119.

Liu H, Mazarati AM, Katsumori H, Sankar R, Wasterlain CG (1999). Substance $P$ is expressed in hippocampal principal 
neurons during status epilepticus and plays a critical role in the maintenance of status epilepticus. Proc Natl Acad Sci USA 96: 5286-5291.

Liu S, Wang J, Zhu D, Fu Y, Lukowiak K, Lu YM (2003). Generation of functional inhibitory neurons in the adult rat hippocampus. J Neurosci 23: 732-736.

Lucassen PJ, Fuchs E, Czeh B (2004). Antidepressant treatment with tianeptine reduces apoptosis in the hippocampal dentate gyrus and temporal cortex. Biol Psychiatry 55: 789-796.

Lucassen PJ, Vollmann-Honsdorf GK, Gleisberg M, Czeh B, De Kloet ER, Fuchs E (2001). Chronic psychosocial stress differentially affects apoptosis in hippocampal subregions and cortex of the adult tree shrew. Eur J Neurosci 14: 161-166.

MacQueen GM, Campbell S, McEwen BS, Macdonald K, Amano S, Joffe RT et al (2003). Course of illness, hippocampal function, and hippocampal volume in major depression. Proc Natl Acad Sci USA 100: 1387-1392.

Magarinos AM, McEwen BS, Flugge G, Fuchs E (1996). Chronic psychosocial stress causes apical dendritic atrophy of hippocampal CA3 pyramidal neurons in subordinate tree shrews. $J$ Neurosi 16: 3534-3540.

Magarinos AM, Verdugo JM, McEwen BS (1997). Chronic stress alters synaptic terminal structure in hippocampus. Proc Natl Acad Sci USA 94: 14002-14008.

Malberg JE, Duman RS (2003). Cell proliferation in adult hippocampus is decreased by inescapable stress: reversal by fluoxetine treatment. Neuropsychopharmacology 28: 1562-1571.

Manji HK, Drevets WC, Charney DS (2001). The cellular neurobiology of depression. Nat Med 7: 541-547.

Manji HK, Moore GJ, Rajkowska G, Chen G (2000). Neuroplasticity and cellular resilience in mood disorders. Mol Psychiatry 5: 578-593.

Manji HK, Quiroz JA, Sporn J, Payne JL, Denicoff K, A Gray N et al (2003). Enhancing neuronal plasticity and cellular resilience to develop novel, improved therapeutics for difficult-to-treat depression. Biol Psychiatry 53: 707-742.

Mantyh PW, DeMaster E, Malhotra A, Ghilardi JR, Rogers SD, Mantyh CR et al (1995). Receptor endocytosis and dendrite reshaping in spinal neurons after somatosensory stimulation. Science 268: 1629-1632.

Martin RD (1990). Are tree shrews primates?. In: Martin RD (ed). Primate origins and evolution. Chapman \& Hall: London, UK. pp 191-213.

McEwen BS (1999). Stress and hippocampal plasticity. Annu Rev Neurosci 22: 105-122.

Millan MJ, Lejeune F, De Nanteuil G, Gobert A (2001). Selective blockade of neurokinin (NK)(1) receptors facilitates the activity of adrenergic pathways projecting to frontal cortex and dorsal hippocampus in rats. J Neurochem 76: 1949-1954.

Nakaya Y, Kaneko T, Shigemoto R, Nakanishi S, Mizuno N (1994). Immunohistochemical localization of substance $P$ receptor in the central nervous system of the adult rat. J Comp Neurol 347: 249-274.

Nestler EJ, Barrot M, DiLeone RJ, Eisch AJ, Gold SJ, Monteggia LM (2002). Neurobiology of depression. Neuron 34: 13-25.

Pavlides C, Nivon LG, McEwen BS (2002). Effects of chronic stress on hippocampal long-term potentiation. Hippocampus 12: 245-257.

Pham K, Nacher J, Hof PR, McEwen BS (2003). Repeated restraint stress suppresses neurogenesis and induces biphasic PSA-NCAM expression in the adult rat dentate gyrus. Eur J Neurosci 17: 879-886.

Reynolds GP, Zhang ZJ, Beasley CL (2001). Neurochemical correlates of cortical GABAergic deficits in schizophrenia: selective losses of calcium binding protein immunoreactivity. Brain Res Bull 55: 579-584.

Ribak CE, Nitsch R, Seress L (1990). Proportion of parvalbuminpositive basket cells in the GABAergic innervation of pyramidal and granule cells of the rat hippocampal formation. J Comp Neurol 300: 449-461.

Ribeiro-da-Silva A, Hökfelt T (2000). Neuroanatomical localisation of substance $\mathrm{P}$ in the CNS and sensory neurons. Neuropeptides 34: $256-271$.

Rupniak NM, Kramer MS (1999). Discovery of the antidepressant and anti-emetic efficacy of substance $\mathrm{P}$ receptor (NK1) antagonists. Trends Pharmacol Sci 20: 485-490.

Rupniak NM (2002). New insights into the antidepressant actions of substance $\mathrm{P}$ (NK1 receptor) antagonists. Can J Physiol Pharmacol 80: 489-494.

Sanacora G, Mason GF, Rothman DL, Behar KL, Hyder F, Petroff OA et al (1999). Reduced cortical gamma-aminobutyric acid levels in depressed patients determined by proton magnetic resonance spectroscopy. Arch Gen Psychiatry 56: 1043-1047.

Santarelli L, Gobbi G, Debs PC, Sibille ET, Blier P, Hen R et al (2001). Genetic and pharmacological disruption of neurokinin 1 receptor function decreases anxiety-related behaviors and increases serotonergic function. Proc Natl Acad Sci USA 98: 1912-1917.

Sapolsky RM, Krey LC, McEwen BS (1985). Prolonged glucocorticoid exposure reduces hippocampal neuron number: implications for aging. J Neurosci 5: 1222-1227.

Scotti AL, Bollag O, Kalt G, Nitsch C (1997). Loss of perikaryal parvalbumin immunoreactivity from surviving GABAergic neurons in the CA1 field of epileptic gerbils. Hippocampus 7: 524-535.

Seress L, Abraham H, Paleszter M, Gallyas F (2001). Granule cells are the main source of excitatory input to a subpopulation of GABAergic hippocampal neurons as revealed by electron microscopic double staining for zinc histochemistry and parvalbumin immunocytochemistry. Exp Brain Res 136: 456462.

Sheline YI (2003). Neuroimaging studies of mood disorder effects on the brain. Biol Psychiatry 54: 338-532.

Sheline YI, Gado MH, Kraemer HC (2003). Untreated depression and hippocampal volume loss. Am J Psychiatry 160: 1516-1518.

Shenton ME, Dickey CC, Frumin M, McCarley RW (2001). A review of MRI findings in schizophrenia. Schizophr Res 49: 1-52.

Sloviter RS, Ali-Akbarian L, Horvath KD, Menkens KA (2001). Substance $\mathrm{P}$ receptor expression by inhibitory interneurons of the rat hippocampus: enhanced detection using improved immunocytochemical methods for the preservation and colocalization of GABA and other neuronal markers. J Comp Neurol 430: 283-305.

Sousa N, Almeida OF, Holsboer F, Paula-Barbosa MM, Madeira MD (1998). Maintenance of hippocampal cell numbers in young and aged rats submitted to chronic unpredictable stress. Comparison with the effects of corticosterone treatment. Stress 2: $237-249$.

Sterio DC (1984). The unbiased estimation of number and sizes of arbitrary particles using the disector. J Microsc 134: 127-136.

Stokes PE, Holtz A (1997). Fluoxetine tenth anniversary update: the progress continues. Clin Ther 19: 1135-1250.

Stone DJ, Walsh JP, Sebro R, Stevens R, Pantazopolous H, Benes FM (2001). Effects of pre- and postnatal corticosterone exposure on the rat hippocampal GABA system. Hippocampus 11: 492-507.

Stout SC, Owens MJ, Nemeroff CB (2001). Neurokinin(1) receptor antagonists as potential antidepressants. Annu Rev Pharmacol Toxicol 41: 877-906.

Tattersall FD, Rycroft W, Marmont N, Cascieri M, Hill RG, Hargreaves RJ (1995). Enantiospecific inhibition of emesis induced by nicotine in the house musk shrew (Suncus murinus) by the neurokinin1 (NK1) receptor antagonist CP-99,994. Neuropharmacology 34: 1697-1699.

Tigges J, Shantha TR (1969). A Stereotaxic Brain Atlas of the Tree Shrew (Tupaia glis). Waverly Press: Baltimore, MD. 
Uno H, Tarara R, Else JG, Suleman MA, Sapolsky RM (1989). Hippocampal damage associated with prolonged and fatal stress in primates. J Neurosci 9: 1705-1711.

Vaid RR, Yee BK, Shalev U, Rawlins JN, Weiner I, Feldon J et al (1997). Neonatal nonhandling and in utero prenatal stress reduce the density of NADPH-diaphorase-reactive neurons in the fascia dentate and Ammon's horn of rats. J Neurosci 17: 5599-5609.

van der Hart MG, Czeh B, de Biurrun G, Michaelis T, Watanabe T, Natt $\mathrm{O}$ et al (2002). Substance $\mathrm{P}$ receptor antagonist and clomipramine prevent stress-induced alterations in cerebral metabolites, cytogenesis in the dentate gyrus and hippocampal volume. Mol Psychiatry 7: 933-941.

van Kampen M, Kramer M, Hiemke C, Flugge G, Fuchs E (2002). The chronic psychosocial stress paradigm in male tree shrews: evaluation of a novel animal model for depressive disorders. Stress 5: 37-46.

Vizi ES, Kiss JP (1998). Neurochemistry and pharmacology of the major hippocampal transmitter systems: synaptic and nonsynaptic interactions. Hippocampus 8: 566-607.

Vollmann-Honsdorf GK, Flugge G, Fuchs E (1997). Chronic psychosocial stress does not affect the number of pyramidal neurons in tree shrew hippocampus. Neurosci Lett 233: 121-124.

Vermetten E, Vythilingam M, Southwick SM, Charney DS, Bremner JD (2003). Long-term treatment with paroxetine increases verbal declarative memory and hippocampal volume in posttraumatic stress disorder. Biol Psychiatry 54: 693-702.

Vreugdenhil M, Jefferys JG, Celio MR, Schwaller B (2003). Parvalbumin-deficiency facilitates repetitive IPSCs and gamma oscillations in the hippocampus. J Neurophysiol 89: 1414-1422.

Wada Y, Shiraishi J, Nakamura M, Hasegawa H (1995). Prolonged but not acute fluoxetine administration produces its inhibitory effect on hippocampal seizures in rats. Psychopharmacology (Berlin) 118: 305-309.

Watanabe Y, Gould E, Daniels DC, Cameron H, McEwen BS (1992). Tianeptine attenuates stress-induced morphological changes in the hippocampus. Eur J Pharmacol 222: 157-162.

West MJ (1999). Stereological methods for estimating the total number of neurons and synapses: issues of precision and bias. Trends Neurosci 22: 51-61.

West MJ, Slomianka L, Gundersen HJ (1991). Unbiased stereological estimation of the total number of neurons in the subdivisions of the rat hippocampus using the optical fractionator. Anat Rec 231: 482-497.

Wong ML, Licinio J (2001). Research and treatment approaches to depression. Nat Rev Neurosci 2: 343-351.

Zhang ZJ, Reynolds GP (2002). A selective decrease in the relative density of parvalbumin-immunoreactive neurons in the hippocampus in schizophrenia. Schizophr Res 55: 1-10. 